Esta obra forma parte del acervo de la Biblioteca Jurídica Virtual del Instituto de Investigaciones Jurídicas de la UNAM

\title{
REFLEXIONES SOBRE LA ELECCIÓN DEL 7 DE JUNIO \\ DE 2015. DE LA COMPLEJIDAD DE LA JORNADA AL EFECTO DEL VOTO
}

Lorenzo Córdova Vianello $^{1}$

\section{Sumario}

\section{Premisa}

II. Las razones de la complejidad de las elecciones de 2015

III. Comentario final sobre el pluralismo y el efecto del voto

\section{PREMISA}

Probablemente, la fortaleza más relevante de nuestro sistema democrático tiene que ver con la dimensión electoral. Hace apenas tres décadas la impermeabilidad del sistema político frente al creciente pluralismo, así como a buena parte de las demandas sociales y dada la poca o nula credibilidad del sistema electoral (particularmente en lo relacionado a las instituciones y los procedimientos electorales), hacían de las elecciones un problema transversal y sistémico en México. Hoy las cosas son radicalmente distintas. A través de las elecciones han cobrado carta de naturalización entre nosotros fenómenos típicamente democráticos, como son los resultados competidos, la alternancia, la ausencia de mayorías predefinidas, los gobiernos divididos, y se ha venido consolidando la única incertidumbre jurídicamente permitida en una democracia: la incertidumbre sobre el ganador. En este marco temporal, el cambio político ha sido profundo, y el pluralismo se recrea periódicamente a través de la vía de los comicios - como ocurre naturalmente en toda democracia-. La organización de las elecciones, por otra parte, pasa por sofisticados procesos técnicos que son presenciados y auditados permanentemente por los partidos políticos, y cada una de las decisiones de la autoridad

\footnotetext{
${ }^{1}$ Presidente del Instituto Nacional Electoral e investigador en el Instituto de Investigaciones Jurídicas de la UNAM.
} 
Esta obra forma parte del acervo de la Biblioteca Jurídica Virtual del Instituto de Investigaciones Jurídicas de la UNAM

que organiza las elecciones son susceptibles de ser impugnadas por los actores políticos y por los ciudadanos.

Este modelo se puso a prueba una vez más en las elecciones del 7 de junio de 2015, y a pesar de la complejidad -y lo abigarrado-que con el tiempo y las sucesivas reformas electorales han llegado a tener las normas que regulan la organización de las contiendas, de nueva cuenta se constató la viabilidad del modelo electoral que hemos construido, y los comicios se reivindicaron, una vez más, como la vía privilegiada para procesar la conflictividad de la diversidad política de la sociedad mexicana por vías pacíficas. Sin embargo, como nunca antes, se presentaron una serie de fenómenos que volvieron a estas elecciones, sin medias tintas, las más complejas de nuestra historia moderna.

Un primer balance de las elecciones no puede dejar de lado el abordar el conjunto de razones que hicieron de estas elecciones las más complicadas de las que se han organizado en México; ello permitiría contextualizar y valorar correctamente las lecciones que se derivan de este proceso electoral de cara al futuro de nuestra democracia. Comienzo señalando los tres conjuntos de razones que explican la complejidad de los comicios de este 2015.

\section{LAS RAZONES DE LA COMPLEJIDAD DE LAS ELECCIONES DE 2015}

Las elecciones de 2015 han sido las más complejas que se han organizado en nuestro país desde la creación del entonces IFE, en primera instancia, por las dimensiones de su organización. Se trata, indudablemente, de las elecciones más grandes de nuestra historia democrática, comenzando porque tuvimos el padrón electoral más grande hasta ahora, con 87.3 millones de registros, y el listado nominal (que representa el número de inscritos en el padrón que efectivamente cuentan con su credencial para votar actualizada), que llegó a 83.5 millones de potenciales electores.

Se trató, por otra parte, del listado nominal más depurado, de mayor cobertura y más confiable de todos los que hemos tenido para organizar una elección legislativa; incluso, es de mayor calidad y confiabilidad que el de 1991, cuando se construyó desde cero el padrón electoral, ${ }^{2}$ y no obstante que ese primer padrón electoral se conformó a partir de

\footnotetext{
2 De acuerdo con la Verificación Nacional Muestral 2015, en 1997 la cobertura de empadronados fue de 90.8\%; en 2012 llegó a 97.6\%, que representó el máximo nivel de cobertura en la etapa del modelo electoral
} 
Esta obra forma parte del acervo de la Biblioteca Jurídica Virtual del Instituto de Investigaciones Jurídicas de la UNAM www.juridicas.unam.mx

la buena fe, y el actual, en cambio, es el resultado de múltiples procesos de actualización, depuración y verificación.

El crecimiento en el número de potenciales electores detonó en cascada una serie de indicadores que determinaron las inéditas dimensiones de la elección de 2015: a) el número de casillas a instalar, cerca de 148,833 (casi 6,000 más que en 2012); b) el número de ciudadanos que debieron insacularse para seleccionar a los funcionarios de casilla, que por mandato de ley se amplió del 10 al 13\% del padrón electoral, lo cual supuso un incremento de $30 \%$ en el número de visitas domiciliarias por cada uno de los 39,000 capacitadores del INE, cambio normativo que implicó pasar de casi ocho millones de visitas en 2012 a cerca de once millones de hogares visitados en 2015; c) el número de elecciones concurrentes, dieciséis o diecisiete si se incluye a Chiapas que acudió a las urnas el tercer domingo de julio, y d) el número de funcionarios requeridos para operar las casillas (alrededor de 1.21 millones) aumentó drásticamente frente al dato de la última elección (900,000 hace tres años). La complejidad cuantitativa anterior no incluye lo relativo a la innovadora figura de la casilla única, la cual operó en las entidades con elecciones concurrentes y que supuso un conjunto de complejidades operativas que tuvieron que resolverse por primera vez y una muy sofisticada coordinación logística con los órganos electorales locales, y que le imprimió a la elección pasada una serie de inéditas dificultades técnicas y logísticas.

En segundo lugar, la complejidad de la elección también se derivó de las nuevas atribuciones que la reforma electoral de 2014 otorgó al Instituto Nacional Electoral. El INE "heredó" del Instituto Federal Electoral la totalidad de las atribuciones que aquél detentaba, con la única excepción de la resolución de los procedimientos especiales sancionadores. Antes el IFE era la instancia que indagaba, sustanciaba y resolvía estos procedimientos; ahora, el INE sólo investiga las quejas que se presentan, y quedó en manos de la nueva Sala Especializada del Tribunal Electoral del Poder Judicial de la Federación la competencia para resolver estos procedimientos administrativos.

Con esa salvedad, el resto de las facultades que tenía el IFE pasaron a formar parte de

federal, y ahora, en 2015, se ha logrado superar ese nivel con una cobertura de $97.7 \%$. Lo mismo sucede con el porcentaje de ciudadanos credencializados, esto es, la relación de aquellos que tienen credencial vigente, respecto de la población de dieciocho años y más. Este indicador también supera los niveles históricos alcanzados por el entonces IFE: en 1997 la cobertura de credencializados fue de 87.7\%; en 2012 alcanzó 92.7\%, y para 2015, con base en los datos del proyecto de acuerdo que está a su consideración, pasó a 95.8\%. 
Esta obra forma parte del acervo de la Biblioteca Jurídica Virtual del Instituto de Investigaciones Jurídicas de la UNAM www.juridicas.unam. $\mathrm{mx}$

las funciones del INE. Pero, además, la reforma de 2014 supuso que la nueva institución ejercería 74 nuevas atribuciones, de las cuales 53 están relacionadas con novedosas competencias de la naciente autoridad nacional en el ámbito de las elecciones locales. Lo anterior no significó solamente un problema numérico de las funciones a ejercer, sino que también trajo aparejada la necesidad de un despliegue operativo y un esfuerzo logístico mayor a los efectuados en otras elecciones previas y en plazos más breves. En efecto, la nueva institución tuvo que emplear sus nuevas atribuciones desde el momento mismo de su conformación, y con la reducción de un mes completo en el calendario de preparación del proceso electoral.

El ejemplo más palpable de lo anterior es que apenas se integró formalmente el INE y de inmediato tuvo que llevar a cabo la compleja elección interna del PRD, instrumentando, por primera vez, la reciente atribución de organizar una elección interna en tiempos muy acotados. ${ }^{3}$ Para dimensionar lo que significó la elección interna de dirigentes de ese partido político basta señalar que el despliegue operativo en el país fue en diversos aspectos similar al de la organización de una elección federal.

Otra tarea adicional que realizó el INE antes de iniciar formalmente el proceso electoral en octubre de 2014 fue la validación de más de 10.6 millones de firmas recabadas para respaldar las cuatro consultas populares que se propusieron en 2014, en congruencia con los plazos establecidos en la también nueva Ley Federal de Consulta Popular. El tema no fue menor, pues supuso que el INE capturara cada uno de los registros presentados -que fueron entregados en papel- como respaldo de ciudadanos para poder compulsarlos con la base electrónica del padrón electoral. Tal validación, que por ley tuvo que efectuarse en menos de treinta días, se realizó de manera exitosa, ${ }^{4}$ pese a que las consultas populares no se llevaron a cabo por

\footnotetext{
${ }^{3}$ De hecho fue más acotado del establecido legalmente. El texto de ley dispone que la solicitud debe hacerse con cuatro meses de anticipación al arranque del proceso electoral interno del partido político. Sin embargo, debido a que se incluyó un transitorio que abría la posibilidad de que si existía una solicitud tramitada al momento de aprobar la ley, no aplicaba dicho plazo.

${ }^{4}$ Con posterioridad, la Suprema Corte de Justicia de la Nación determinó que ninguna de las cuatro consultas populares reunía los requisitos de constitucionalidad necesarios, y por lo tanto anuló su realización. La secuencia con la que el INE y la SCJN ejercen sus atribuciones debería cambiarse en el futuro para que el trabajo de verificación de firmas a cargo de la autoridad electoral se realice sobre consultas ciertas en su constitucionalidad, pero eso implica inevitablemente una modificación legal.
} 
Esta obra forma parte del acervo de la Biblioteca Jurídica Virtual del Instituto de Investigaciones Jurídicas de la UNAM

determinación de la Suprema Corte de Justicia de la Nación.

Un factor más que contribuyó a la complejidad del proceso electoral de 2014-2015 fue el carácter del INE como autoridad nacional que le otorgó la reforma electoral. Esta reforma, al modificar la estructura de la administración electoral de todo el país con la intención de estandarizar las condiciones en las que se desarrolla la competencia electoral, le otorgó al INE la responsabilidad de designar y remover a los consejeros integrantes de los organismos públicos locales electorales (OPLEs), y de establecer lineamientos y criterios que garanticen los mismos parámetros de aplicación de las leyes electorales por parte de las autoridades locales de todo el país. Para decirlo claramente, de una elección a otra, el IFE dejó de ser una autoridad exclusivamente federal y se convirtió en una nueva entidad nacional rectora de un nuevo modelo electoral.

Para ilustrar lo anterior basta con señalar que entre las facultades nacionales que quedaron a cargo del INE se encuentran: la designación de los consejeros integrantes de los OPLEs; la revisión de los gastos de precampaña y campaña de todos los precandidatos y candidatos tanto locales como federales; la administración única de los tiempos del Estado en la radio y la televisión para efectos electorales; la elaboración del padrón electoral, la credencial para votar y la lista nominal de electores; la definición del Estatuto del Servicio Profesional Electoral Nacional (a partir del servicio profesional que operó en su momento el IFE); un grupo de atribuciones especiales que permitirían asumir o delegar total o parcialmente las funciones de organización de las elecciones locales; la instalación de casillas únicas cuando se celebren elecciones locales concurrentes con las federales, y la emisión de lineamientos y criterios para la celebración de encuestas electorales, conteos rápidos y programas de resultados electorales preliminares.

Esta concepción de un sistema nacional de elecciones con atribuciones entreveradas multiplicó los vasos comunicantes entre el INE y los OPLEs, con objeto de fortalecer técnicamente a las autoridades locales, por lo que fue necesario intensificar los instrumentos y mecanismos para la colaboración entre los dos tipos de autoridades electorales que coexisten por mandato constitucional, y sincronizar el ejercicio de las atribuciones legales. Todo esto con el fin, insisto, de estandarizar la calidad de las contiendas.

Así, en cumplimiento a lo dispuesto por la reforma, el Instituto diseñó un proceso de 
Esta obra forma parte del acervo de la Biblioteca Jurídica Virtual del Instituto de Investigaciones Jurídicas de la UNAM www.juridicas.unam. $\mathrm{mx}$

selección riguroso, ${ }^{5}$ objetivo, transparente y verificable para elegir en septiembre de 2014, con paridad de género, a los mejores perfiles para ocupar los órganos de dirección de diecinueve entidades: a las dieciséis con elecciones concurrentes; a los integrantes del OPLE de Oaxaca, que tendría elecciones por usos y costumbres en 2015; a los consejeros de Chiapas, que celebraron su jornada electoral el 19 de julio, y a las y los consejeros del OPLE de Zacatecas en acatamiento a una sentencia del Tribunal Electoral del Poder Judicial de la Federación. Asimismo, a cinco meses de haber entrado en funciones el INE designó a 133 consejeros electorales de diecinueve OPLEs: Baja California Sur, Campeche, Colima, Chiapas, Distrito Federal, Estado de México, Guanajuato, Guerrero, Jalisco, Michoacán, Morelos, Nuevo León, Oaxaca, Querétaro, San Luis Potosí, Sonora, Tabasco, Yucatán y Zacatecas. Estos nombramientos se realizaron. ${ }^{6}$

La contraparte de esta designación en el contexto del sistema nacional fue conformar una Unidad Técnica, que dispuesta en la Legipe, se encargara de darle seguimiento a la organización de las contiendas locales y suscribir para ello convenios de colaboración con cada OPLE, en los que se precisen puntualmente los ámbitos de competencia de ambas instituciones en relación con el proceso electoral. El propósito de estos convenios es evitar que el entreveramiento de atribuciones y la existencia de facultades especiales que podrían llevar a asumir, delegar o atraer ciertas actividades de la función electoral, por parte del INE, generen confusiones en el desarrollo del proceso electoral. Además, emitimos lineamientos para la implementación de programas de resultados electorales preliminares, conteos rápidos, encuestas electorales, fiscalización e, incluso, para el voto de los mexicanos residentes en el extranjero, debido a que algunas entidades tenían disposiciones en esta materia.

Otra novedad de la reforma electoral que constituyó un verdadero desafío para el INE

\footnotetext{
${ }^{5}$ El procedimiento de selección contempló seis etapas sujetas a los principios rectores de la función electoral, de transparencia y máxima publicidad: convocatorias públicas en cada entidad; registro de aspirantes; verificación de los requisitos legales; examen de conocimientos; ensayo presencial, y valoración curricular y entrevista.

${ }^{6}$ Debe señalarse que la segunda fase de selección y designación de consejeras y consejeros de los OPLEs se realizó el 30 de octubre de 2015. También se llevó a cabo mediante un concurso público, en el cual se buscó experiencia y trayectorias para integrar órganos colegiados multidisciplinarios. Al término de estos dos concursos, el de 2014 y el de 2015, se aprobaron 224 nombramientos, de los cuales 117 fueron para mujeres, y 107, para hombres. Así, de los 32 OPLEs del país, 15 son presididos por presidentas, y 17, por presidentes.
} 
Esta obra forma parte del acervo de la Biblioteca Jurídica Virtual del Instituto de Investigaciones Jurídicas de la UNAM

fue instrumentar el nuevo modelo de fiscalización inédito en México y en el mundo, que convirtió esta atribución en una responsabilidad de alcance nacional. La polémica que se generó a partir de la revisión y auditoría de los ingresos y egresos de los partidos políticos efectuadas por el IFE en 2012 incentivó el diseño de un nuevo modelo de fiscalización, el cual se convirtió en una de las columnas vertebrales del naciente sistema nacional de elecciones. Para plantearlo de manera esquemática podría decirse que los propósitos de dicho modelo se articularon a partir de tres ejes: 1) el carácter nacional de la fiscalización; 2) la exhaustividad en la revisión, y 3) el registro de operaciones en línea para favorecer la oportunidad.

Para cumplir con tales propósitos se hizo necesario adecuar el diseño institucional (de la concepción, estructura e integración) de la Unidad Técnica de Fiscalización; revisar y actualizar los reglamentos y procedimientos administrativos en materia de fiscalización, y desarrollar un conjunto de herramientas informáticas que permitieran a los partidos políticos registrar y clasificar sus operaciones financieras y contables durante las precampañas, campañas, así como reconocer la naturaleza jurídica de las operaciones que realicen con terceros.

En cuanto al primer eje - el carácter nacional de la fiscalización -, la reforma dispuso que sería el INE la instancia responsable de establecer los criterios y procedimientos para las revisiones, confrontas, verificaciones y auditorías que se realicen a los ingresos y egresos de los partidos políticos y candidatos federales y locales. La idea de los legisladores es que los resultados sean comparables, y obligar con ello a que los partidos políticos instrumenten un control mucho más riguroso de sus finanzas y la administración del financiamiento que reciben.

En cuanto al eje de la exhaustividad, lo más relevante fue que se mantuvo esta característica de la fiscalización, pero con los tiempos acortados. Cabe recordar que hasta 2012 se fiscalizaba prácticamente un año después de concluidas las campañas, y cuando todos los cargos emanados de dicha elección estaban ya ocupados por los ganadores. Ahora no. A diferencia del pasado cuando la fiscalización y la validación de las elecciones corrían de manera autonómica, hoy la fiscalización y la validación de las elecciones están alineados, y uno depende del otro. Dicho de otra manera, la validación de las elecciones sólo es posible si ha concluido la fiscalización.

En cuanto al tercer eje del modelo de fiscalización —el registro de operaciones en 
Esta obra forma parte del acervo de la Biblioteca Jurídica Virtual del Instituto de Investigaciones Jurídicas de la UNAM www.juridicas.unam. $\mathrm{mx}$

línea para que sea oportuna-, las disposiciones legales derivadas de la reforma electoral fueron completamente novedosas. La intención de los legisladores fue modelar un sistema que permitiera revisar los ingresos y los gastos de los partidos políticos prácticamente en tiempo real, para estar en condiciones de cumplir con los nuevos plazos y que los resultados de la fiscalización sean conocidos antes de que se califiquen las elecciones por parte de las instancias jurisdiccionales. Ello es debido a que ahora una causal de nulidad es el rebase de los topes de gastos de campaña y que la diferencia entre la votación del primero y segundo lugar sea inferior al 5\%. En tal sentido, los resultados de la fiscalización son insumos fundamentales para que el Tribunal Electoral realice su tarea de validación de las propias elecciones, y que los ganadores puedan ocupar legalmente los cargos para los que fueron electos.

Para instrumentar este modelo fiscalizador fue necesario adecuar las estructuras institucionales vinculadas a las auditorías, los reglamentos, la normatividad y los procedimientos involucrados, así como desarrollar un sistema de contabilidad en línea que facilitara la presentación y revisión de los informes de los partidos políticos y los candidatos. Al respecto, cabe mencionar que de acuerdo con el reglamento aprobado por el Consejo General del INE, los partidos políticos tienen tres días para cargar en el sistema todos los ingresos y los gastos que realicen, a partir del momento en que se efectúen. ${ }^{7}$

Visto en perspectiva, este sistema de contabilidad en línea no sólo es inédito por el volumen de información que procesa simultáneamente, sino también porque fue creado en un tiempo récord (los técnicos dicen que el diseño de la arquitectura de una plataforma informática de esta naturaleza tarda entre seis meses y un año, y el INE tenía menos de un año para que el sistema estuviera operando).

Originalmente hicimos una licitación internacional para que algún desarrollador pudiera construir este programa, dada la sobrecarga de tareas que entonces tenía la

\footnotetext{
${ }^{7}$ Esta decisión fue resultado de una discusión institucional intensa, en la que el Banco de México, con quien tuvimos una cercanía importante en la fase de conceptualización del sistema informático, nos puso sobre aviso para que no permitiéramos que pasaran más de tres días para que los partidos cargaran la información, con objeto de evitar la posibilidad de que se creara una contabilidad paralela o maquillada. En efecto, durante la discusión del reglamento, los partidos pedían que les diéramos cinco días para poder cargar la información; pero le hicimos caso al Banco de México y establecimos tres, y el sistema funcionó adecuadamente para ser su primera experiencia.
} 
Esta obra forma parte del acervo de la Biblioteca Jurídica Virtual del Instituto de Investigaciones Jurídicas de la UNAM

Unidad de Servicios de Informática del INE en el desarrollo de otros sistemas indispensables para el proceso electoral.

Sin embargo, el 14 de diciembre de 2014 la empresa ganadora (cuyo CEO tuvo un enorme espacio en algunos medios de información) incumplió la entrega del primer módulo del sistema. Este hecho detonó no sólo nuestras alarmas institucionales, sino también el arranque de un procedimiento de rescisión del contrato, en tanto la empresa había decidido unilateralmente que nos iba a entregar tres meses después del plazo convenido ese primer módulo. Tal determinación se dio tres días antes de que arrancaran las precampañas, momento en el cual ese módulo tenía que estar operando, y el retraso eliminaba prácticamente toda posibilidad de prueba y de retroalimentación sobre el funcionamiento del sistema.

Ante este hecho optamos por hacer un desarrollo propio con el respaldo informático de la UNAM, y en tres meses logramos tener operando un sistema, tal vez menos robusto de lo que originalmente se había pensado, pero que claramente cumplía con los propósitos centrales de la reforma electoral en esta materia.

Actualmente, el INE es titular de los derechos de un sistema que, además de que nos permitió cumplir en tiempo y forma con el mandato constitucional y legal de concluir la fiscalización para que sirva de insumo al TEPJF, constituye un desarrollo informático que eventualmente puede ser compartido con autoridades electorales de otros países del mundo.

Con este sistema y la adecuación institucional efectuada, la fiscalización de 2015 obligó a los partidos políticos y candidatos a tener un mayor control administrativo sobre los recursos ejercidos en las contiendas y facilitó la rendición de cuentas de éstos ante la sociedad. De ahí que, en julio de 2015, la implementación de la fiscalización nacionalizada derivó en la revisión de 24,230 informes, que involucran 12,912 candidaturas tanto federales como locales. Dichos informes implican que, en conjunto, el INE auditó 3,110.5 millones de pesos, a escasos 43 días de concluida la jornada electoral. Lo anterior significa que se revisaron quince veces más informes de los fiscalizados por el IFE en 2012, y ello representó la auditoría de 19.4\% más recursos que en aquella elección.

Algunos datos adicionales que ayudan a dimensionar el trabajo de fiscalización realizado son los siguientes: se revisaron más de 1,069,000 operaciones incorporadas al 
Esta obra forma parte del acervo de la Biblioteca Jurídica Virtual del Instituto de Investigaciones Jurídicas de la UNAM www.juridicas.unam.mx

sistema de contabilidad en línea; se recorrió, por primera vez, la totalidad de los 300 distritos uninominales para detectar la propaganda en vías públicas, con lo cual se obtuvieron 40,066 testigos georreferenciados (incluyen bardas, espectaculares y mantas), y en los estados con elección de gobernador se recorrieron, adicionalmente, tres veces los distritos que conforman a la entidad; se recibieron el $94.6 \%$ de los informes de gastos de campaña que debieron presentar los candidatos (únicamente el $5.4 \%$ incumplió con esta obligación); se conformó un padrón nacional de proveedores con 18,897 registros, y debido a la innovación de la contabilidad en línea, fue necesario analizar de manera tradicional un tercio del total de operaciones registradas por partidos y candidatos.

Entre los resultados relevantes de la aplicación del modelo de fiscalización nacional por parte del INE pueden destacarse los siguientes: $\left.{ }^{8} 1\right)$ no se presentó el supuesto de que algún candidato ganador hubiera rebasado el tope de gastos y que el margen de victoria hubiera sido inferior al $5 \%$; 2 ) únicamente catorce candidatos federales y quince locales rebasaron los topes de gastos de campañas, lo cual habla del ejercicio de contención y control administrativo que llevaron a cabo los partidos y los candidatos, ante lo radical de la sanción que podría haberse aplicado; 3) los catorce candidatos federales que rebasaron los topes de gastos de campaña representan el $0.03 \%$ de los 4,496 que compitieron, dato que si se contrasta con los 195 candidatos que en 2012 rebasaron los topes, habla del control financiero y administrativo que sí pueden realizar los contendientes.

En cuanto a las sanciones derivadas de la fiscalización, conviene señalar que el monto acumulado de estas sanciones asciende a 389.2 millones de pesos. De éstos, 130.4 millones corresponden a las campañas federales, y 258.8 millones, a las locales; el partido más sancionado fue el PVEM con 72.9 millones, que representan el $18.75 \%$ del total sancionado a los partidos políticos; el segundo partido con mayores multas por este concepto fue el PAN con 51.5 millones (13.23\% del total de sanciones), seguido por el PRD con 39.1 millones (10.06\% del total) y MC con 37.4 millones (9.63\%). En esta elección, el partido menos sancionado fue Nueva Alianza con 4.1 millones de pesos $(1.07 \%$ del total de las sanciones impuestas por el INE).

Desde mi perspectiva, es indudable que el nuevo modelo de fiscalización fue uno de los mayores desafíos que enfrentó el INE en la organización del proceso electoral 2014-

\footnotetext{
${ }^{8}$ Cifras actualizadas hasta julio de 2015.
} 
Esta obra forma parte del acervo de la Biblioteca Jurídica Virtual del Instituto de Investigaciones Jurídicas de la UNAM www.juridicas.unam. $\mathrm{mx}$

2015, y está destinado a convertirse en una herramienta central para transparentar la actividad política de quienes compiten por el voto y para consolidar el sistema de partidos en la nueva etapa de la democracia mexicana.

Otro componente inédito de la dificultad que implicó la organización del pasado proceso electoral se derivó del contexto y de la complejidad social que se vive en nuestro país.

Nunca antes la organización de una elección se había desarrollado en un contexto tan adverso como el que se vivió entre 2014 y 2015, tanto por factores estructurales como por situaciones coyunturales que claramente quedaban fuera del ámbito electoral.

Para ilustrar los problemas estructurales que afectan la democracia mexicana basta con recordar unas cifras. De acuerdo con el estudio de Gerardo Esquivel Hernández sobre Desigualdad extrema en México, en nuestro país al 1\% más rico de la población le corresponde el $21 \%$ del ingreso total, mientras que en otros países, como Nueva Zelanda, España, India o Australia, a ese mismo 1\% más rico le corresponde un promedio cercano al $10 \% .{ }^{9}$ Otro indicador que cita Esquivel para mostrar la lamentable desigualdad que se padece en México es el "Coeficiente de Gini", ya que mientras acá tenemos un coeficiente de 0.441 , el promedio de los países incluidos en la Standardized World Income Inequality Database $^{10}$ es de 0.373 .

En el mismo sentido, datos de la OCDE revelan que la pasada recesión ha provocado un incremento en los niveles de desigualdad, pues para 2014 la brecha entre los ingresos del $10 \%$ de los mexicanos más ricos frente a los más pobres pasó de $26.8 \%$ al $28.5 \%$, y el porcentaje de personas que reportan no tener suficiente dinero para comprar comida se incrementó del 31.9\% al 38.3\%. ${ }^{11}$ Más aún, de acuerdo con el Informe país sobre la calidad de la ciudadanía, el $75 \%$ de los mexicanos dijo no conocer a alguien que lo pueda ayudar a defenderse ante una injusticia, y $66 \%$ considera que la ley se respeta poco 0

\footnotetext{
${ }^{9}$ Esquivel Hernández, Gerardo, Desigualdad extrema en México. Concentración del poder económico y político, México, OXFAM, p. 15.

${ }^{10}$ Este indicador mide la desigualdad de ingresos al interior de un país, y significa que mientras más cercano a cero sea el resultado, mayor será la igualdad. Ibidem, p. 12.

${ }^{11}$ Véase indicadores sociales de la OCDE 2014, www.oecd.org/social/societyataglance.htm.
} 
Esta obra forma parte del acervo de la Biblioteca Jurídica Virtual del Instituto de Investigaciones Jurídicas de la UNAM www.juridicas.unam.mx

nada. ${ }^{12}$ Es comprensible que estos datos se reflejen en una percepción de debilidad del Estado de derecho, en ámbitos como el de la inseguridad, y que incidan negativamente en la percepción y en la eventual decepción de la democracia, como lo ha señalado el Informe Latinobarómetro en los últimos años.

En cuanto a los aspectos coyunturales que generaron un ambiente adverso a la organización de las elecciones, podríamos ubicarlos en dos planos por lo menos: el de la inseguridad y el de la conflictividad social.

Respecto al de la inseguridad, no es, desafortunadamente, una circunstancia novedosa para la autoridad electoral en la organización de las elecciones. Ya el IFE en su momento tuvo que enfrentarse en 2009, y particularmente en 2012, para cumplir con su mandato constitucional, a un contexto de inseguridad que cambiaba día a día y que ya entonces representaba focos de alerta para la operación electoral en distintas zonas del país.

Afortunadamente, el Instituto (antes IFE ahora INE), por su diseño institucional, cuenta con una enorme capacidad de adecuación en distintas circunstancias y coyunturas, que le ha permitido sortear con éxito los desafíos de la inseguridad, y debo decirlo con todas las letras: la criminalidad nunca ha tenido como propósito boicotear las elecciones, ni impedir la operación electoral. Este dato es relevante, ya que la organización electoral implica una operación de campo muy extensa (probablemente tan extensa como la que realiza el INEGI cada diez años). No exagero al señalar que ningún otro órgano del Estado realiza cada tres años un despliegue territorial tan amplio como el que lleva a cabo el INE en todas las zonas del país de manera simultánea. En tal sentido, el tema de la inseguridad que se vive en algunas zonas se convierte en una circunstancia que nos obliga a aprobar una serie de protocolos que permitan al personal de las juntas distritales desplegar esa capacidad de amoldamiento que le ha dado viabilidad a la logística electoral. Mal habríamos hecho en tratar desde el Consejo General del INE de dictar protocolos de actuación que tuvieran aplicabilidad en todo el país. Los protocolos en esta materia se deben realizar a partir de las situaciones específicas de cada zona y que son mejor conocidas por nuestro personal en cada distrito.

En fin, la inseguridad claramente no es un tema nuevo. Lamentablemente es un tema

${ }^{12}$ Informe país sobre la calidad de la ciudadanía en México, México, IFE-Colmex, 2014. 
Esta obra forma parte del acervo de la Biblioteca Jurídica Virtual del Instituto de Investigaciones Jurídicas de la UNAM

que forma parte, digámoslo así, de la vida ordinaria de nuestra sociedad, con distintas modalidades y en diversas zonas del país. De ahí que el INE actúe tomando en consideración el conocimiento específico de cada región y distrito, y a partir de ello se realicen los protocolos para hacer frente a las particularidades sobre el tema de la inseguridad y no hacer de éste, que es uno de los grandes problemas nacionales, un impedimento para la operación institucional. Dicho en otras palabras, la inseguridad no fue y no ha sido un obstáculo insalvable para el trabajo del Instituto Nacional Electoral.

El segundo plano del contexto adverso considero que sí es absolutamente inédito: la conflictividad social que ha enfrentado el país en los últimos meses. Desde la movilización en Guerrero por los terribles acontecimientos de Iguala el 26 de septiembre de 2014, hasta la movilización magisterial en muchas zonas del país en contra de la reforma educativa, pasando por una pléyade de movimientos, de organizaciones sociales, que clamaban demandas, siendo muchas de ellas legítimas. Tales movilizaciones por primera vez en nuestra historia aparejaron sus demandas a la amenaza de impedir las elecciones si no eran atendidas.

Esta situación fue completamente inédita. Por supuesto, no me refiero a que los problemas nacionales que tenemos, como los de pobreza, desigualdad, inseguridad e impunidad que ya mencioné, que son ominosos y que forman parte de las asignaturas pendientes, puedan ser soslayados por nuestro sistema democrático. Pero es claro para los actores de las movilizaciones y para amplios sectores de la sociedad, que son conflictos que no se resuelven en las urnas. Ésa es la novedad. La solución a esas demandas se trasladó a la organización electoral bajo la amenaza del boicot de las elecciones; además, no fueron exclusivamente el Movimiento Popular Guerrerense ni la capacidad organizativa de la CNTE en algunas entidades donde tiene presencia gremial importante, activa y beligerante.

Para darle cauce y construir las condiciones que permitieran la celebración de las elecciones en todo el país fue necesario que el INE se reuniera con múltiples actores: con los padres de los estudiantes desaparecidos de Ayotzinapa; ${ }^{13}$ con representantes de distintos grupos indígenas, los cuales también amenazaban con no permitir las

\footnotetext{
13 Fue una reunión muy dura, muy intensa, muy franca. Al final del día llegamos a una serie de compromisos que cumplimos, pero evidentemente ellos aparejaban, como es conocido públicamente, la aparición de los jóvenes a cambio de permitir las elecciones.
} 
Esta obra forma parte del acervo de la Biblioteca Jurídica Virtual del Instituto de Investigaciones Jurídicas de la UNAM www.juridicas.unam.mx

elecciones si no registrábamos candidatos de representación proporcional en una sexta circunscripción que planteaban que se creara en pleno proceso electoral; con productores cafetaleros, que ante la caída de los precios del café y la falta de apoyos del gobierno estatal en Chiapas bloquearon y amenazaron con impedir la elección en Huixtla, e incluso con transportistas agraviados, porque no se había cumplido la promesa de campaña de las autoridades locales de pavimentar un tramo carretero, quienes no sólo bloquearon nuestras instalaciones en el municipio, sino también las vandalizaron. ${ }^{14}$

Con los ejemplos anteriores lo que quiero establecer es que nunca antes se había planteado la solución de demandas sociales como condición para que se desarrollaran las elecciones. Pareciera que se ha transversalizado la circunstancia de hacer rehén a las instituciones del Estado para lograr el cumplimiento de demandas, legítimas o no, a través de la amenaza del boicot electoral. Esto es algo que se debe reflexionar, pues desafortunadamente los grandes problemas nacionales o de una comunidad (como la pavimentación de una pequeña carretera) no deberían ser utilizados para impedir el ejercicio de los derechos políticos de una comunidad. En este sentido, si se repite el contexto de conflictividad social que experimentamos en 2015 en los meses previos a las elecciones de 2018, pensando en la trascendencia que la renovación de los poderes públicos tiene para la estabilidad política del país y la institucionalidad democrática (y en la gran apuesta política que implican las elecciones presidenciales), el discurso del boicot electoral se puede volver mucho más atractivo, y su negociación y solución podría representar costos políticos aún más altos que en 2015.

\section{COMENTARIO FINAL SOBRE EL PLURALISMO Y EL EFECTO DEL VOTO}

Concluyo haciendo referencia a algunas cifras $y$, principalmente, con algunas de las lecciones que nos deja este proceso electoral.

Primero. La jornada del 7 de junio de 2015 en muchos sentidos es una elección exitosa, sobre todo si se toma en cuenta el contexto y la complejidad en la que se tuvo que llevar a cabo. Esto incluye las cifras del número de casillas instaladas $(148,648)$ y de

\footnotetext{
14 Aquí es necesario hacer una aclaración: las instalaciones del INE son claves para desarrollar la elección. De hecho, la infraestructura telemática del Instituto, de la que dependen nuestros sistemas de información, requiere que podamos operar en nuestras instalaciones, por lo cual durante los procesos electorales las instalaciones del INE adquieren el carácter de instalaciones estratégicas del Estado mexicano.
} 
Esta obra forma parte del acervo de la Biblioteca Jurídica Virtual del Instituto de Investigaciones Jurídicas de la UNAM www.juridicas.unam.mx

las no instaladas (185). Ciertamente, 185 son muchas si se compara con el éxito que alcanzó el IFE en la elección de 2012, cuando únicamente dejamos de instalar dos (ambas en Oaxaca por conflictos intercomunitarios). Hoy se dejaron de instalar 185, pero 100 de ellas corresponden a un distrito en Oaxaca, porque literalmente se bloqueó la carretera de acceso en el distrito de Teotitlán.

Debo mencionar que el ejército no pudo liberar, y creo que lo hizo por prudencia, el acceso carretero, pues había un grupo muy grande y beligerante de profesores que estaba impidiendo el acceso.

SEGUNDO. Al final del día, la buena llegada a puerto de las elecciones es producto de la acción concertada del Estado mexicano, particularmente en el estado de Oaxaca, ya que en las 48 horas previas a la jornada electoral se llevó a cabo un despliegue consistente de fuerzas del orden, el cual permitió que se celebrara la jornada en esa entidad. Para dimensionar este hecho basta con mencionar que una semana antes del 7 de junio estaban bloqueadas alrededor de treinta juntas distritales.

TeRCERO. En Oaxaca tuvimos que adelantarnos, sin publicitarlo, en la distribución de los paquetes electorales hacia los presidentes de casilla. Así, cuando se bloquearon las once juntas distritales en Oaxaca, con la excepción de la Junta de Huajuapan de León, en todas las demás habíamos ya logrado sacar los paquetes electorales. Nos tuvimos que adelantar al calendario. La fecha programada decía que teníamos que empezar esta distribución el lunes previo a la elección y lo hicimos el domingo, anticipando que el lunes bloquearían las instalaciones.

Es decir, el saldo es que logramos instalar la inmensa mayoría de las casillas y pudimos hacer las elecciones en todos los distritos. Ciertamente, hubo momentos en los que se llegó a considerar, incluso, la posibilidad de eventualmente cancelar elecciones en algunos distritos; pero no lo hicimos, porque se estaban creando, con el apoyo de instituciones del Estado, autoridades locales y con la solidaridad de organizaciones sociales, las condiciones para que las casillas pudieran instalarse en los trescientos distritos del país, y digámoslo así, las votaciones transcurrieron como siempre desde la década de los noventas en un clima de relativa calma.

CUARTO. Tuvimos recuentos que terminaron el 12 de junio en la madrugada en los trescientos distritos electorales. A partir de ello, en veinte distritos se realizó el recuento total de las casillas; esto es un número mayor al de 2009, que fue la primera elección 
Esta obra forma parte del acervo de la Biblioteca Jurídica Virtual del Instituto de Investigaciones Jurídicas de la UNAM

donde se aplicaron las causales para el recuento total y parcial. En efecto, mientras en 2009 se recontaron diecinueve distritos en su totalidad, en 2015 recontamos veinte. El número de casillas recontadas es el más grande de la historia en una elección legislativa: estamos hablando de más del $61 \%$ de paquetes electorales recontados, y además se constató en los recuentos que lo registrado por los ciudadanos en las actas era, en términos generales, preciso.

QUINTO. Las coincidencias de los sistemas de información preliminar del INE con las cifras de los cómputos distritales son prácticamente totales. Las variaciones entre el conteo rápido, el PREP y los cómputos distritales fueron absolutamente marginales: en particular, si se toma en cuenta que el conteo rápido es una herramienta estadística; normales, si se piensa que el PREP, aunque es una práctica censal, no llega nunca al $100 \%$ (alcanzamos un 98.6\%), y en especial, que ambos mecanismos estuvieron perfectamente alineados con los cómputos distritales.

Sexto. Ciertamente tuvimos una falla en los sistemas de difusión de resultados, pero considero que se exageró la dimensión de la falla. Dicho error se dio en la pantalla de consulta pública, pero no en la operación de los sistemas, y menos aún influyó en los resultados. Indudablemente habrá que revisar tales aspectos en un ejercicio de autocrítica, y para ello ordenamos una auditoría a nuestros sistemas informáticos. Puede que haya quien diga "que los sistemas fallaron como nunca"; pero también es necesario reconocer que, como nunca, en esta elección tuvimos que desviar los esfuerzos de nuestro personal de programación e informática, que tradicionalmente se dedica al desarrollo de los sistemas que utiliza el INE en las elecciones, a construir el sistema de fiscalización, el cual —como ya mencioné- se elaboró en tiempo récord y que requirió de la concentración de buena parte de nuestros recursos técnicos.

SÉPTIMO. El porcentaje de votación es un porcentaje muy satisfactorio, en especial si se piensa en el contexto en el que la elección estaba llevándose a cabo. El porcentaje de participación ciudadana ascendió al 47.72\%; dicho porcentaje es el mayor de las últimas tres elecciones legislativas: en 2003 tuvimos 41.68\%; en 2009, 44.61\%, y hoy, 47.72\%. En otras palabras, en esta elección se volvió a desvirtuar la idea presente en el imaginario colectivo de que las elecciones intermedias tendían a la baja. Más aún, ahora deberíamos decir que la participación ciudadana en las elecciones intermedias está cerrando gradualmente la brecha entre los porcentajes de participación en las contiendas presidenciales. 
Esta obra forma parte del acervo de la Biblioteca Jurídica Virtual del Instituto de Investigaciones Jurídicas de la UNAM

OCTAVO. El porcentaje de votos nulos es también el menor respecto de las tres últimas contiendas. Pasamos de 5.4\% en 2009; a 4.9\% en 2012, y a 4.7\% en esta jornada electoral. No estoy menospreciando lo que el voto nulo significa, pero creo que la gran lección de la jornada electoral, más allá de los números, que por lo demás demuestran una organización eficaz a pesar del contexto adverso, es que todavía estamos lejos de los números de una democracia consolidada.

Los ocho puntos anteriores, a mi parecer, configuran un buen resultado. Aún son números preliminares que, a reserva del balance de la elección, el cual también debe ser una construcción colectiva como la misma democracia, tendrán que complementarse con los que aporte la academia, la opinión pública y los partidos políticos. ${ }^{15}$

En síntesis, desde mi perspectiva, el balance del proceso electoral de 2014-2015 es positivo, por lo menos, en siete aspectos:

1) Logramos exorcizar la amenaza del boicot de las elecciones, y esto es producto de la prudencia de la actuación de la autoridad electoral; de la generación de condiciones por parte de las instancias públicas, particularmente federales, para crear un clima en el que las elecciones pudieran llevarse a cabo, es decir, un piso mínimo de orden y de seguridad; pero, sobre todo, del compromiso ciudadano que reivindicó e hizo suya la elección, y con ello la vía electoral, como una vía privilegiada para defender algo que ha sido una de las grandes conquistas en los últimos treinta años: el poder del voto.

Actualmente, las elecciones ya son una ruta privilegiada para procesar el intenso pluralismo que caracteriza a nuestra sociedad por vías pacíficas, y considero que el porcentaje de participación es un porcentaje contundente de la reivindicación de la vía electoral, frente a quienes eventualmente a partir de demandas, sin duda legítimas, habían colocado el tema de la elección como una condición o como una moneda de cambio.

\footnotetext{
${ }^{15}$ Debo señalar que en este artículo no incluí el tema de las nulidades de las elecciones locales y federales, aunque seguramente dará mucho de qué hablar en el sistema nacional de elecciones, no sólo por la afectación de los derechos políticos de quienes sí se apegaron a las reglas del juego democrático, sino también por las consecuencias institucionales de organizar desde el INE diversas contiendas municipales, en paralelo a la participación en otras elecciones ordinarias. Esta exclusión obedece a que a la conclusión de este texto estaban en proceso de análisis y resolución en el TEPJF diferentes impugnaciones, entre las que destaca la elección de gobernador en Colima, la del distrito federal 01 de Aguascalientes, entre otras contiendas municipales y distritales en Guerrero, Michoacán y Querétaro, principalmente.
} 
Esta obra forma parte del acervo de la Biblioteca Jurídica Virtual del Instituto de Investigaciones Jurídicas de la UNAM

2) Otra lección de este proceso electoral es que el voto cuenta, que el voto sirve. Tuvimos alternancia en 102 distritos electorales federales. En efecto, en la tercera parte de los distritos electorales federales hubo alternancia en la fuerza política ganadora. Además, la alternancia se produjo en gubernaturas y congresos locales: se dio en cinco de las nueve elecciones de gobernador, y en cinco entidades de las dieciséis en las que se renovaron a los congresos locales cambió la fuerza política mayoritaria.

3) Se probó una nueva figura para la competencia electoral que, aunque efectivamente está sujeta a normas muy complejas, demostró ser una ruta viable, no necesariamente la más privilegiada, pero sí viable para acceder al poder político. Éste es el caso de las candidaturas independientes. Es de subrayar que en todos los niveles de representación política disputados el 7 de junio hubo al menos un ganador por la vía de las candidaturas independientes: un candidato independiente ganó una gubernatura; otros lo hicieron en las diputaciones federales; algunos se convirtieron en diputados locales, y otros más fueron alcaldes. Estos triunfos se obtuvieron como se consiguen los triunfos electorales en una democracia: por la vía de los votos.

4) Tenemos una sociedad, y creo que este es un efecto de demostración muy positivo de esta elección, que se comprometió con la recreación de la vida democrática, como una manera de incidir en el futuro político del país, y que se empodera del ejercicio de sus derechos políticos, como una forma de decirle no al boicot de las elecciones y no a las imposiciones políticas. Ésta es, según mi perspectiva, la gran buena noticia: que tenemos una sociedad que cree en la vía electoral. Estas elecciones demuestran que los mexicanos asumimos el voto como una manera de refrendar algo que ya es parte de la democracia mexicana: el intenso pluralismo político que la cruza, y esto es algo que nos debe llevar a reflexionar en múltiples planos.

5) En algunos sectores de nuestra sociedad se dice que tenemos muchos partidos. Pero los votantes dijeron otra cosa: votaron por ocho partidos de manera clara. En 2015, el sufragio se atomizó. El partido más votado no alcanzó el $30 \%$ de la votación; el segundo con mayor respaldo electoral obtuvo el $21 \%$; en un rango de $11 \%$ y $6 \%$ se ubicaron cuatro partidos, y apenas superando el umbral del $3 \%$ se localizaron dos partidos más. Dicho de otra manera, entre el $3 \%$ y el $11 \%$ se encontraron las votaciones de seis partidos políticos, y este segmento del electorado representó un tercio de los votantes. 
Esta obra forma parte del acervo de la Biblioteca Jurídica Virtual del Instituto de Investigaciones Jurídicas de la UNAM

6) En México, el pluralismo político forma parte de nuestra realidad; no hay mayorías predefinidas; no las hay por decisión de los ciudadanos en las urnas; tenemos alternancias y gobiernos divididos. Eso sí es parte del escenario político de México en los últimos dieciocho años, desde 1997. Ésta es la correlación de fuerzas con la que tienen que convivir instituciones y partidos políticos. Estas elecciones repitieron aquello que en 1994 se atribuyó al voto, es decir, entonces se decía que era una manera de decirle "no" a un tipo de violencia política (distinta evidentemente a la que hoy tenemos); pero consideramos que estas elecciones nos sirvieron como sociedad para reivindicar algo que es una conquista de todos, que es precisamente la vía electoral como una vía para procesar y recrear ese intenso pluralismo y, principalmente, para incidir en el futuro político del país.

7) Los datos anteriores me parece que comprueban que las nuevas reglas del juego democrático claramente contribuyen a la competitividad de las contiendas, y a fortalecer en la joven democracia mexicana tres principios de un sistema democrático: 1) la alternancia; 2) la aceptabilidad de la derrota, y 3) la incertidumbre sobre el ganador.

Concluyo recordando que hace treinta años las elecciones eran uno de nuestros mayores problemas, al menos de los problemas políticos sin duda. Hoy las elecciones se muestran como la ruta privilegiada de los ciudadanos para procesar por vías pacíficas el intenso pluralismo que caracteriza a nuestra sociedad.

En México, los votos cuentan, y la sociedad se empoderó del voto para incidir en la política y en la distribución del poder político. El pasado 7 de junio se probó un nuevo modelo electoral que es viable y contribuye a la equidad de la competencia. La jornada electoral ratificó que los mexicanos queremos un país plural, y que elige sus poderes públicos en las urnas. El país que vimos el 7 de junio es un país de ciudadanos convencidos para salir a la calle y participar en las elecciones; es un país de gente que quiere decidir en paz e influir en el futuro político.

En el nuevo modelo electoral, las reglas del juego democrático favorecen la competitividad y pueden derivar en la alternancia en cualquier ámbito de la competencia (municipal, distrital, estatal o federal). Los cambios en la correlación de fuerzas a nivel federal y en las elecciones locales demuestran que en México los ciudadanos determinan quiénes ocuparán los poderes públicos, y que cada elección constituye una oportunidad 
Esta obra forma parte del acervo de la Biblioteca Jurídica Virtual del Instituto de Investigaciones Jurídicas de la UNAM www.juridicas.unam. $\mathrm{mx}$

para retirarlos o ratificarlos.

La solución de los grandes problemas nacionales no se logra en un día ni en un proceso electoral. Las campañas electorales sirven para discutir prioridades políticas, y las urnas, para sancionar o respaldar las que deben ser consideradas como prioritarias por parte de quienes se sumarán a la representación política. Pero claramente en las urnas no se resuelven los problemas ancestrales. Eso depende de las políticas públicas. Espero que la movilización social que se dio el 7 de junio se transforme en una sociedad mucho más participativa, mucho más exigente, que haga uso de sus derechos -incluido el derecho a la protesta - como una manera de poder incidir en las políticas públicas, para presionar la pronta resolución a los grandes problemas nacionales, porque ha quedado demostrado que si bien éstos no son exclusivos de la materia electoral, sí pueden afectar el desarrollo de las elecciones. Si queremos elecciones con menos sobresaltos, resolver los temas de la pobreza, de la desigualdad, de la impunidad y de la corrupción sería una buena manera de construir el contexto favorable a la recreación de la vida democrática. Tal vez las elecciones serían más aburridas, pero sin lugar a duda generarían menos sobresaltos, como los que ocurrieron en 2015. 